\title{
Seismic potential of the Cascadia subduction zone
}

\section{Garry C. Rogers}

THE two main conclusions that emerged from a special session at a recent meeting* are that the Cascadia subduction zone appears to be storing strain, and that there are numerous examples of suddenly buried wetland-soil horizons that seem to be best explained as examples of past great earthquakes. Although some speakers suggested that there are special conditions that could prevent great earthquakes, such as the high temperatures of the young subducting slab (J. Severinghaus, University of California, Santa Barbara) or the abundant offshore sediments (D.E. Byrne, Lamont-Doherty Geological Observatory; L.R. Sykes, Lamont-Doherty), none offered alternative explanations for the data that support the 'great earthquake' hypothesis. The outcome of the debate has more than passing interest for the ten million people who live in the vicinity of the zone and could be affected by a great earthquake.

The Cascadia subduction zone is a small subduction zone that straddles the Canada-United States border on the west coast of North America (see figure). It involves several small oceanic lithospheric plates (the last remnants of the large Farallon plate) that are actively subducting beneath North America. Low-angle thrust earthquakes, characteristic of most subduction zones around the world, have not been observed there. Detailed monitoring by seismic networks on both sides of the border over the past decade shows that, although small earthquakes are common in the overlying and descending plates, thrust earthquakes at the subduction interface are absent even at the microearthquake level. The question thus arises as to whether subduction is taking place aseismically or whether the region is in an interseismic period between great earthquakes. With this seismological information, strain measurements and studies of the recent (the past 12,000 years) geology of the region becoming available, the question could soon be answered.

The search for geological evidence of past great earthquakes is focused on identifying coastal features that indicate sudden changes of elevation relative to sea level. There are no recent marine terraces along the Cascadia subduction zone to suggest that sudden emergence events have occurred (D.O. West, Golder Associates). But the hypothesis put

- American Geophysical Union fall meeting, 7-11 December 1987, San Francisco. forward by B.F. Atwater, of the US Geological Survey (USGS), in Science (236, 942-944; 1987), that sequences of buried wetland soils on the outer coast of Washington State represent a series of sudden down-drops generated by large subduction earthquakes, received considerable support.

A search for such buried-soil horizons by several investigators reveals that they extend from southern Oregon (A.R.

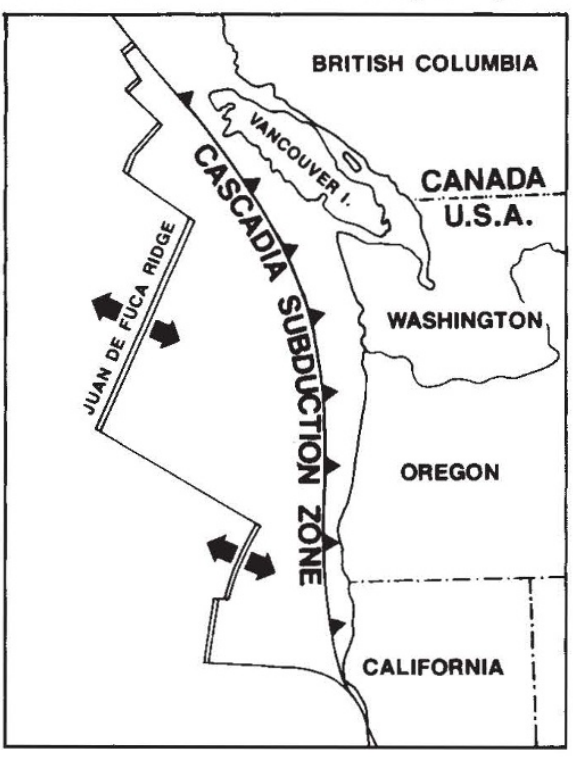

The Cascadia subduction zone of western North America. Oceanic lithosphere created at the nearby Juan de Fuca Ridge system subducts beneath the North American Plate.

Nelson, USGS) to southern Vancouver Island (my own work). The most complete sequence has been found in large estuaries on the outer coast of Washington (Atwater; A.G. Hull, University of California, Santa Barbara) and indicates that submergence events occurred about $300,1,000,1,500,1,700,2,500,2,800$ and 3,500 years ago. The presence of sand layers, interpreted by Atwater as tsunami deposits, help to mark the areal extent of some events (M.A. Reinhart, University of Washington; W.C. Grant, USGS). Investigations in smaller estuaries, particularly those in Oregon, are confusing, as buried soil layers are found, but not always (Nelson; Grant; C. Peterson, Oregon State University). It is clear that

\section{Erratum}

In the table of the article "How to live with radon" by Michael O'Riordan (Nature 331, 302; 1988), the term 'per cent' should have referred only to the absolute lifetime risk and not to the relative lifetime risk of exposure to radon. mapping the extent of these suddenly buried soils, dating them and further research into their origin is important.

The essential results of horizontal strain measurements in the subduction region are that wherever measurements have been attempted, strain appears to be accumulating with a principal axis of shortening that is parallel to the modelled direction of plate motion (M. Lisowski, USGS; H. Dragert, Geological Survey of Canada; N.A. Breen, Lamont-Doherty). Repeated horizontal control surveys comparing older surveys with modern laser ranging or global-positioning satellite measurements show that shear strain is accumulating at a rate of about 0.2 parts per million per year, comparable to rates in other subduction zones such as Japan, New Zealand and Alaska, where large thrust earthquakes have occurred in historic times. These measurements support the hypothesis that the subduction zone is locked and strain is currently accumulating in the upper plate.

Measurements of vertical motion are also consistent with strain accumulation across a locked subduction zone. Changes of sea level at tidal stations in the northern part of the zone reveal a characteristic two-dimensional pattern that would result from the oceanic plate dragging down the edge of the continental plate (my own work). Integrating precise levelling data with tide gauge data shows a complex areal distribution of vertical motion but one that is also consistent with strain accumulation (S.R. Holdahl, US National Geodetic Survey). The patterns of vertical and horizontal motion at the north end of the subduction zone are complicated by deformation caused by large crustal earthquakes (Holdahl; Dragert).

A two-dimensional finite element elastic model of the subduction zone with reasonable estimates for input parameters is found to fit observed strain measurements best when the subduction zone model is locked and close to an impending earthquake (H.J. Melosh, University of Arizona). Current observations, however, are too sparse to provide diagnostic constraints for the model.

Before the arguments presented at the meeting lead us to believe in a cycle of great earthquakes on the Cascadia zone, the sudden subsidence events must be dated accurately and correlated over a large area. Similarly, strain must be shown to be accumulating over a large area. The evidence seems to be sufficient, however, to place the onus on the sceptics of the great-earthquake hypothesis to provide convincing alternative explanations for the observations. Until now, none has emerged.

Garry C. Rogers is at the Geological Survey of Canada, Pacific Geoscience Centre, Sidney, British Columbia V8L 4B2, Canada. 